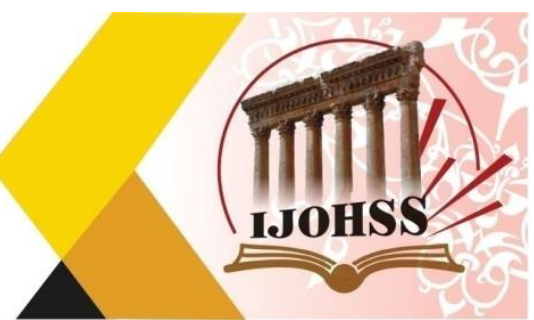

\title{
Discourse Markers in Selected English Editorials: A Communicative Aspect Between Text Producers and Receivers
}

\author{
Asma Asaad Thamer \\ Department of English, College of education for Women \\ Al-Iraqia University \\ Iraq \\ Email: asmaa.thamer@aliraqia.edu.iq
}

\begin{abstract}
Discourse markers (DMs) are those elements which show the writer's linguistic and rhetorical manifestation for the information that used in the text. The aim of this paper is to show the importance of discourse markers (DMs) in editorial texts of two English newspapers, the Guardian and the New York Times. To fulfill the goals of the study, the function of these DMs in editorials will be analyzed according to their qualitative contributions. The results and findings of this research show that the function of these DMs are different. A great variety of occurrence of DMs can be seen between textual and interpersonal genres. Interpersonal DMs achieve certain goals or roles in the study. This leads to a conclusion that though the function of DMs is different, a similar aspect in which how text producers try to instruct their readers in a way that their attitudes and discourses can be easily understood leads to fulfill the tenor of communication.
\end{abstract}

Keywords: interpersonal function, textual function, metadiscourse markers, code glosses. 


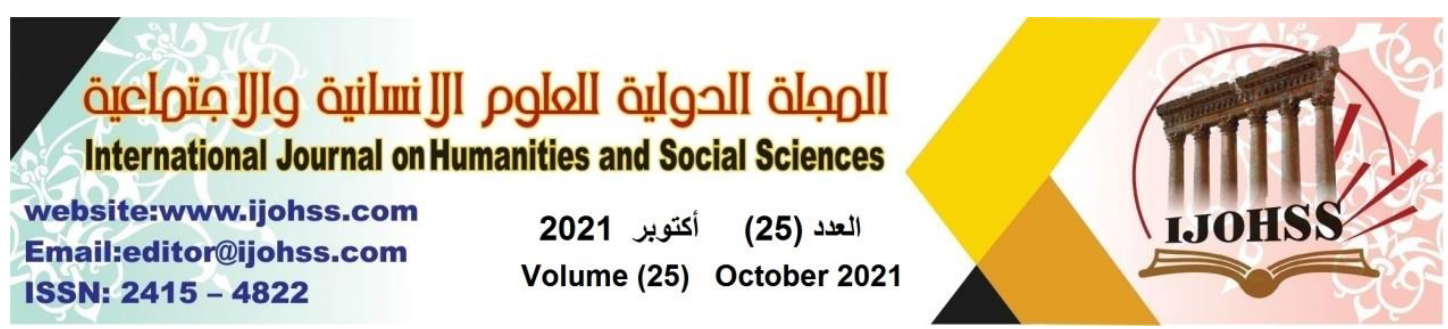

\subsection{Introduction}

The role of discourse markers DMs is very important to achieve the goal of language as a means of communication in written and spoken discourse. Sometimes if these DMs are not used in the discourse, it sounds like something missed from the sentence to be understood or to add a communicative aspect to it. Kohlani states that though DMs are optional in use, they are pragmatically obligatory because they are key elements in text production and perception (2010: 5) while Brinton (1996) states that DMs on the interpersonal and textual level of any discourse achieve different pragmatic functions. Actually, their importance lay through being predicted by the receiver of a discourse and in some cases not using DMs will breakdown the process of communication. Their use in any text give naturalness to that text.

The editorials are that part of written media discourse. DMs, which connect any pieces of writing, can fulfill to summarize, to conclude or to indicate an attitude which is an essential factor in writing an editorial. In addition, logical markers can function as transitions from discourse unit to another and interactional discourse markers can imply the reader in the argument, interaction or exchange.

The data used in this paper consists of some editorials from the Guardian and the New York Times newspapers. The subject of editorials are of many issues, economic, social, political and religious one. Some clarifications of these DMs within the editorials whether they are of textual or interpersonal functions will be identified. The occurrence of textual function of DMs are more than that of interpersonal one which leads to conclude that DMs which link the text are of a great importance in the editorial or any piece of written or spoken discourse due to their role of making the text more cohesive and understood while the importance of DMs as interpersonal function lies in strengthening the link between the author and reader of the text through expressing the authors' attitude, evaluation, etc.

The paper adopts the two classes of textual and interpersonal DMs with their role and function in the selected editorials as they help to organize the discourse, show the engagement of the readers to the text and the attitudes and viewpoints of text producers to the text they supply their readers with.

\subsection{Discourse Markers and Literature Review:}

This subject has been the concern of a lot of researchers for many centuries with a lot of contributions being made to this matter so let's shed the light on their definition and classification. Fraser (1999) labeled DMs as "discourse markers", "discourse connectives", "discourse operators", "discourse pragmatics", "sentence connectives", and "cue phrases". There is no a consensus about how they can be defined or work but according to the opinions of previous researchers of this topic, they agree that DMs relate to adverbs, conjunctions or prepositional phrases. I agree with Fraser 's opinion (1999) that they relate to the class that suit them most according to the function they do but Fraser in his article states that other researcher like Zwickly does not mention any proof that those DMs form a class but mentions that "Discourse 


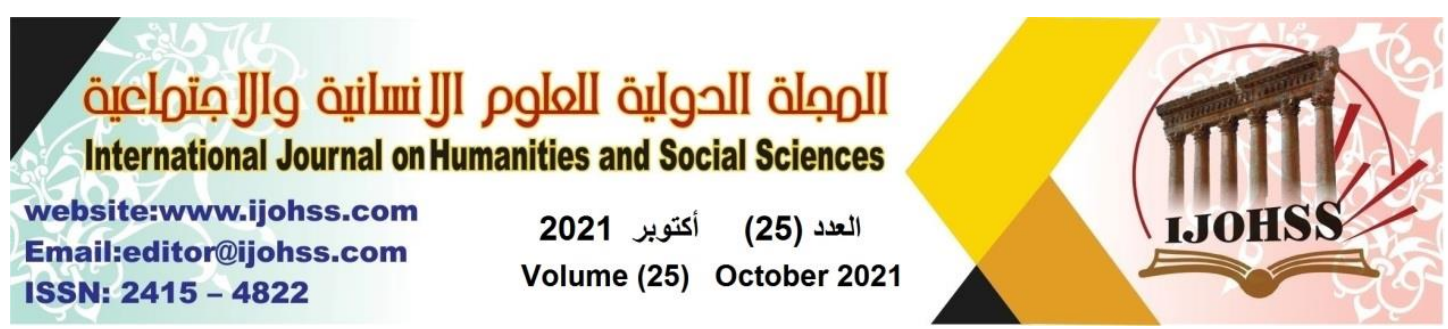

markers ALL have the latter, pragmatic functions [e.g. the role of relating the current utterance with a larger discourse] rather than the former, narrowly semantic, ones" [e.g. indicating sentence type] (1985: 303-304). Redeker describes DMs as discourse operators and explains them as "a word or phrase, for instance, a conjunction, adverbial, comment clause, interjection that is uttered with the primary function of bringing to listener's attention a particular kind of the upcoming utterance with the immediate discourse context" (1991: 1168). In this case, if the author wants to attract the listeners' or readers' attention to the next utterance, he will make a bond between him and the reader to make the process of communication in progress.

There are many approaches that deal with DMs among them what was mentioned by schiffrin et al (2001: 57) who state that DMs connect utterances on a single or different planes. The planes that they offer within a discourse are ideational structure, exchange structure, action structure, information state and a participation framework.

They also claim that DMs involve a set of linguistic elements like conjunction (andbut- for), adverb (now- then), interjection (oh), and other lexical phrases as (I meanyou know).

Another approach is done by Fraser (1996: 2) who is interested in grammatical and pragmatic perspective. He distinguishes between 'propositional and nonpropositional content'. The propositional meaning is represented when the speaker draws attention of the addressee to something while 'everything else' represents the 'non- propositional content'. Those non- propositional part of the sentence analysed as 'pragmatic markers' which donates different messages. Fraser states that DMs which occur in the sentence are of four types: topic exchange markers like 'by the way- back to my original point', contrastive markers like 'in contrast- though- but', elaborative markers like 'in particular- above all- furthermore' and inferential markers like 'consequently- all things considered' (1996: 3). Later on, as quoted from Piurku (2015: 17), according to Fraser, DMs can be defined as "lexical expressions, drawn from the syntactic classes of conjunctions, adverbs and non-propositional phrases, which signal a relationship between the interpretation of the segment they introduce, $\mathrm{S} 2$, and the prior segment, S1" (1999: 950).

The third approach which concerns us here is that of Blakemore $(1987,2002)$ who was interested in "relevance theory". Discourse connectives are used to show how one item in discourse relevants to another. They constrain the procedure of utterance interpretation. For instance, expressions like after all, but, so, therefore affect the interpretation of an utterance in the context (1987: 75). After that, Blakemore claims that the relevance of information utterance can be conveyed through four ways which are: the implication of a context may be concluded or derived 'so- therefore- too', an existing assumption may be strengthen by giving an evidence for it 'furthermore- after all- moreover', an existing assumption may be 


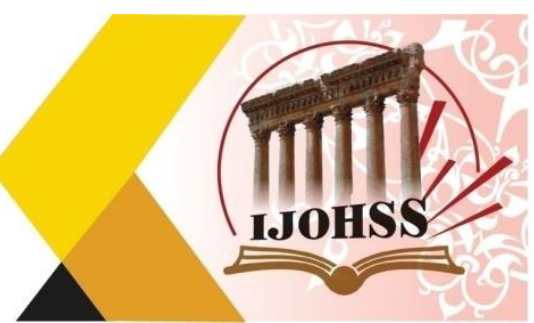

contradicted 'but- however- nevertheless' and finally the role of utterance may be specified 'anyway- finally- by the way'.

I can conclude that the most important thing is their interrelationship; when those segments occur in the sentence they correlate with each other. For instance, what is prior refers to what is later and these interrelationship gives continuity to the sentence meaning which is important to the communicative aspect of using any text or discourse.

\subsection{The textual function of discourse markers}

Many researchers deal with the textual function of DMs directly or indirectly. The textual function of what concern us here is represented through cohesive relations. According to Halliday (1994), these cohesive relations are conjunctive relations in which the elements of the text refer to each other's. They include 'additive, adversative, causal, and temporal relations'. While according to Brinton, the textual function of pragmatic markers are many among them: their uses of starting and closing discourse to bring the attention of the hearer, presenting a new topic and denoting an old or new information, and indicating sequential or relevance dependence (1996: 35). The communicative aspect and the essential role of DMs can be shown clear by referring to Aijmer's point of view $(2002,41)$ when he states that it's function at frame textual is marking transitions which include: introducing direct speech, a new turn and an explanation. Their qualifiers function are: showing contrast, comparison, agreement or disagreement, and responding to a question.

Now, the distribution and function of discourse markers within the editorials will be discussed. Both textual and interpersonal discourse markers with their divisions will be shown by the selected data that clarify each of these DMs:

\subsection{Connectors:}

They refer to those markers which connect the discourse as its name suggests. They are used by the writer to join the structures of the text in a way which helps the readers to notice the succession of events within the sentence. These connectors or cohesive devices are of many types among them the following subdivisions:

\subsubsection{Additives:}

They function as a means of elaboration to inform the readers that what follows will be additional information that is added to give some more details like 'and, in addition':

- $\quad$ Field Marshal Charles Guthrie, the former head of the armed forces, and others including the ex-defence secretary, Sir Malcolm Rifkind, a former commander of land forces and the ex-head of service prosecutions, have warned Downing Street that soldiers are also at greater risk if Britain is seen to ignore international law. In 


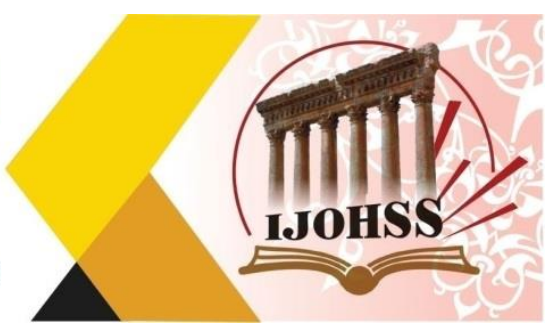

addition, the country's most senior military judge has pointed out that it could become more likely for British personnel to be brought before the international criminal court. (The Guardian )

\subsubsection{Sequencers:}

Sequencers are used when we are talking about steps or orders of doing things for instance when telling stories or giving instructions on how to do things. These sequencers point to a link between different events which are successive. Within the editorials, the writer uses DMs in different viewpoints in series to guide his readers to a link which shows how he has expressed different viewpoints based on their priorities. Among those sequencers are first, second, then, next, after that, and finally.

- $\quad$ Unusual fare for Saturday prime-time, yet the audience lapped it up, whooping in the studio and enthusing on social media. And then the media regulator, Ofcom, was deluged with complaints - well over 20,000 by the start of this week, objecting to its political nature. (The Guardian).

\subsubsection{Adversatives:}

They refer to those linguistic features which are used by the writer of the editorial to signal that his viewpoints this time has a contrastive proposition if it is compared to the previous one. Among those linguistic features are but, however, the other, yet.... . - It is easy to say one thing and do another - to disdain GDP when over $60 \%$ of the population don't know what GDP is. But nor can the public be dismissed as money-obsessed individualists. (The Guardian).

- The other striking theme of the Reset report was how keen respondents were for a more localised, greener economy. (The Guardian).

- But not everyone was hit hard. Germany was barely dented by the eurozone crisis. ( The Guardian).

- $\quad$ Yet there was a new sense of desperation in Mr. Trump's performance. He knows, as most observers do, that he is on track to lose the election. ( The New York Times).

- In this small story lies much that makes people despair of the state of UK democracy: deeply tribalistic, talking past rather than to each other, and with some (notably on the right) nursing their resentments like the dregs of an expensive cocktail. (The Guardian).

- Despite reassurances from the White House on Friday afternoon that Mr. Trump was experiencing only "mild symptoms," he was transported to Walter Reed National Military Medical Center early that evening. (The New York Times)

- However sick the president may be, the truth cannot be more harmful than the thick fog of confusion the White House has created. (The New York Times) 


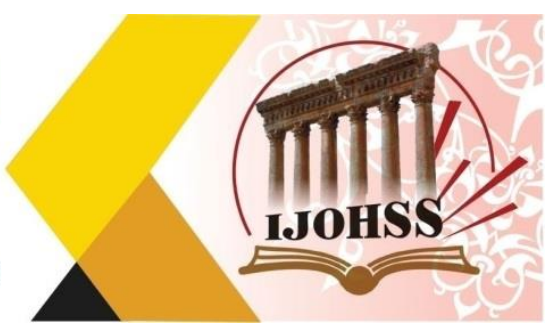

\subsubsection{Causal:}

The linking words are of many groups among them coordinate conjunctives which are 'because, since, thus, consequently, due to and as'. They are used by the writer of the editorial or speaker in the interviews to instruct the readers that those DMs are denoting 'cause' within the text:

- $\quad$ Since localities are principally in charge of enforcement, this is a needed step. (The New York Times)

\section{2 Topicalizers:}

This sort of DMs indicates topic shift to the readers. This function can be achieved by instructing the readers to specific phrases to be as the most important word or phrase within the paragraph: as for, with regard to, in connection to, in this, which is ...

- It is often vulnerable members of these communities, like students who've been denied a basic education, who suffer from that political cowardice. In this case, the health and well-being of every New Yorker is at stake. (The New york Times)

- $\quad$ Yet, as Mr. Putin looks intent on spending the rest of his life at Russia's helm and displays ever less concern for human rights or the rule of law, it is incumbent on the West to hold him accountable for murdering or trying to murder anyone he finds troublesome. (The New York Times)

- $\quad$ Many people don't like this argument because it's seen as a way of letting Trump off the hook. But there's another way of looking at it, which is that while Trump's early failures weren't necessarily worse than our hypothetical "just listen to the experts" president, they were arguably more culpable and tragic — precisely because Trump himself was not a believer in what one expert quoted in my colleagues' story calls "the religion of global health. (The New York Times)

- One problem, as campaigners have often noted, is that, to many people, courts, unlike schools or hospitals, appear remote: a sphere of life in which they have no stake (except perhaps for a few days serving on a jury). The truth is that a weakened justice system affects us all indirectly. (The Guardian)

- What makes the government's silence all the more deafening is that there is no shortage of suggestions. (The Guardian)

\section{3 Code glosses}

The function of code glosses are of two main types. One of them is reformulation while the other is exemplification. The communicative function of code glosses can be shown clearly in written text through which information flow can be managed. Those code glosses are used within the text to elaborate information by using such words as 'for example, which means, such as, called, namely...' and other words which give more explanation or clarification to the readers.

- $\quad$ One of the government's stated objectives is the reinforcement of "shared values" across the UK, which implies a project to bolster unionism and challenge nationalism, especially in Scotland.(The Guardian) 


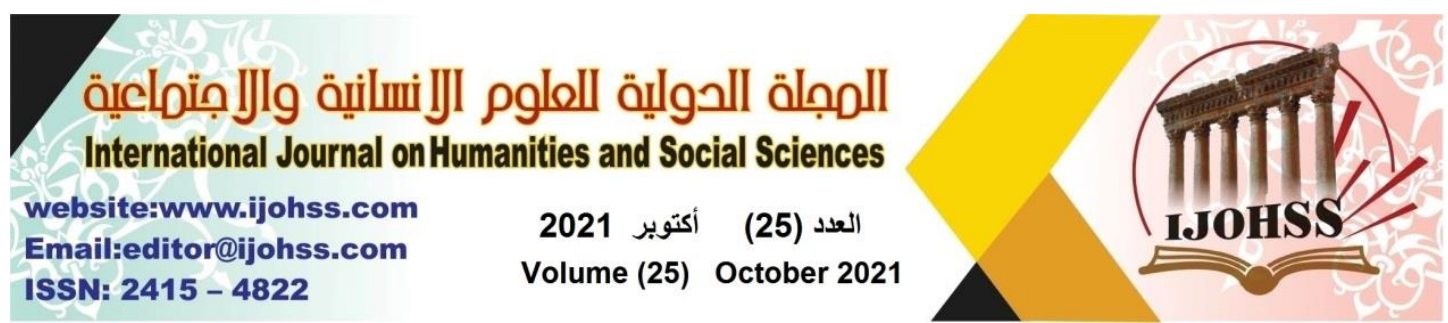

- $\quad$ In a letter to cabinet colleagues, Mr Gove noted that problems at Channel ports will arise "irrespective of the outcome of negotiations". In other words, the Brexit model that is expected to disrupt the passage of freight, increase the burden of bureaucracy, reduce the volume of trade and slow the economy is one chosen by $\mathrm{Mr}$ Johnson. (The Guardian)

\subsection{Interpersonal discourse Markers:}

Discourse markers at the interpersonal level can be used to serve two functions which are subjective and interactive. In the subjective case, the attitude and evaluation of the message by the writer will be obvious and the achievement or establishment of intimacy between both producer and receiver of the written or spoken discourse will be noticed at the interactive case. The intrinsic feature of DMs at this level serve as vehicles which contribute to the maintenance of the relationship between text producer and receiver towards the produced discourse or participants of the communicative situation while the dominant function of DMs at the textual level is to indicate relations between tests segments (Yelmaz, 2004).

According to the data of editorials, this clear relationship between the speaker and the reader can be achieved through the subcategories of interpersonal DMs which are hedges, certainty markers, attitude markers and relational markers. In all these subcategories the writer will involve the readers by one way or another in the communicative act through "appealing to the reader such as 'let us- how could we forget', attracting his attention as in 'most importantly- look', and by guiding his interpretation of the text" (Al Kohlani, 2010: 324). Now, a brief explanation of those subcategories can be identified as follows:

Hyland claims that the interpersonal function of metadiscourse consists of two interactions' dimension: interactive and interactional dimension. The interactive one is divided into the followings: transition markers like 'additive- causative- adversative', frame markers like 'to conclude- finally', evidentials like 'according to', endophoric markers like 'noted above', and code glosses like 'in other words". On the other hand, the interactional resources are evaluative, denoting solidarity, and replying to an imagery dialogue. It means that the interactional dimension deals with the way the writer conducting interaction through commenting on the message (2013: 78). Those interactional markers are subdivided into hedges like 'possible and perhaps', attitude markers like 'surprisingly and unfortunately', boosters like 'it is clear that and in fact', and engagement markers like 'you can see that' (ibid : 80). To sum up, the interactional marker involves the reader or listener in the text while the interactive marker helps to guide the reader or listener through the text.

The interpersonal function of DMs according to Castro ( 2009: 61) involves subjective and interpersonal function. The subjective function is represented through responding to a discourse or an understanding to what have been said by another speaker who turn taking while the interpersonal function involves demanding confirmation, asserting shared supposition, etc. It means that the interpersonal function of DMs according to Castro (2009:71) refers to relations and responses 


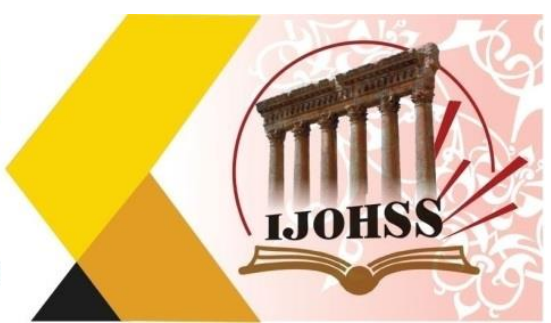

between participants of discourse in which affirms the communicative aspect of DMs through making the discourse goes on and on between the addresser who is the writer and the addressee who represents the reader here.

Another classification is adopted by Kopple (1985: 84), the interpersonal function which represents the attitude of writer to the text are divided into 'illocution markers, attitude markers, and commentaries'. The classification of Kopple has been revised by some researchers. Among revisions are those of Hyland and Tse (2004). According to them, the interpersonal function can be found in all metadiscourse because of its interest in textual experience and knowledge of the reader and because it gives the writer a power or a weapon to accomplish this. In (2005), Hyland states that textual metadiscourse that are recognized as adverbials and conjuncts can be directed as interactional or propositional meaning, "conjunct is a result of our primarily ideational orientation to the world, but we can also see conjunctions as interactionally motivated, contributing to the creation and maintenance of shifting interpersonal orientations" (43). He concludes that texts are organized as 'proposition' through textual devices by relating statements about the world and as 'metadiscourse' through relating statements to the readers. The textual devices do not function freely as proposition or metadiscourse because the latter one is different from propositional aspect of discourse. The metadiscourse function can only be interpersonal (ibid: 43).

\subsection{Hedges:}

This term in linguistics was discussed in detail by the linguists Lakoff (1973). He defines hedges as "words whose meaning implicitly implies fuzziness- words whose job is to make things fuzzier or less fuzz" (p. 471). These markers can be expressed by many words to indicate the partial or full commitment of the truth value of the content of the text in comparison with tone of the statement. The statement which is utilized by the text producer indicates the degree of certainty, less certainty, ability, or probability...etc whether they are expressed by modals verbs, adverbs or quantifiers.

\subsection{Markers of certainty:}

These markers focus on the certainty of the proposition which are conveyed by the needs of the readers in addition to the extent of the author commitments by the strength of the statement in the content of the text. Among those marks are obvious, clearly, inevitable, there is no doubt, definitely....

- $\quad$ it has been obvious that pupils who were then in the first year of two-year exam courses (years 10 and 12) faced potentially damaging consequences. (The Guardian)

- $\quad$ Clearly, the postponement of exams by three weeks cannot make up for a term (or more) of missed classes. (The Guardian)

- As Jeremy Farrar of the Welcome Trust tweeted: "The tragedy is how predictable this has been since at least early July. It was not inevitable. It is not 


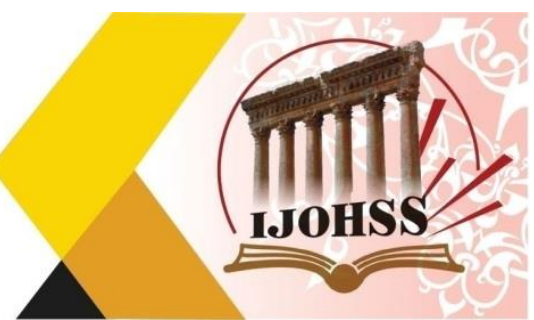

inevitable now that this worsens, but to avoid spiralling out of control [there] needs to be action now." (The Guardian)

\subsection{Attitude markers}

The attitude markers express the author orientation towards the text content in form of agreement, obligation, and so on which can be easily expressed by using adjectives, attitudinal or cognitive verbs as 'surprisingly and I think':

- The conflict in the South Caucasus echoes ongoing, heedless violence in several Middle East countries where, it seems, enmity trumps humanity. War is its own disease. (The Guardian)

\subsection{Relational markers}

Those markers can function in two different ways. In both cases the readers will be involved within the text either by focusing their attention or by involving them directly within the text situation. This focus on the readers can be employed through the use of second person pronoun or naming the person or using imperative forms in the statement.

\section{Conclusion}

As the purpose of using any languages is to communicate and send specific messages to the receiver and in order to make this communication flows smoothly, the interlocutors use some clues which are DMs to perform mutual understanding among them whether at textual or interpersonal level. Those DMs decrease the interpretation of the hearers to the most suitable one that is needed or suggested by the speaker or text producer and also signal the relationship among the interactants or both a speaker and a hearer.

In conclusion, coherence and textuality in discourse are characteristics of the functions that have been analysed on textual macrolevel while reaction, relations, confirming or requesting confirmation and responses are characteristics of interpersonal functions of DMs. Despite differences among researchers subclassifications' of DMs but there is a very little difference in the function itself.

\section{References}

1. Aijmer, K. (2002). English Discourse Particles: Evidence from a corpus. Amsterdam: John Benjamins Publishing Compan.

2. Brinton, L., J. (1996). Pragmatic Markers in English: Grammaticalization and Discourse Functions. Berlin: Walter de Gruyter.

3. Blakemore, D. (1987). Semantic Constraints on Relevance. Oxford: Blackwell.

4. Blakemore, D. (1992). Understanding utterances. Oxford: Blackwell.

5. Castro, C. M. "The Use and Functions of Discourse Markers in EFL Classroom Interaction." Profile: Issues in Teachers' Professional Development, no.11 (2009):5777.Redalyc, https://www.redalyc.org/articulo.oa?id=169214144005

6. Kohlani, M.A. (2010). The Function of Discourse Markers in Arabic Newspaper Opinion Articles. PhD dissertation. Washington: Georgetown University.

7. Fraser, B. (1996). Pragmatic Markers, Pragmatics, 6(2): 167-190. 


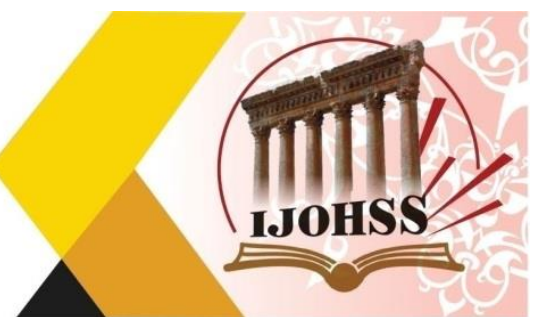

8. Fraser, B. (1999). What are discourse markers? Journal of Pragmatics 31 (1999) 931-952.

9. Halliday, M., A., K. (1994). An Introduction to Functional Grammar. London: Edward Arnold.

10. Hyland, K. \& Tse, P. (2004). Metadiscourse in Academic Writing: A Reappraisal, Applied Linguistics, 25(2): 156-177.

11. Hyland, K.( 2005). Metadiscourse. London: Continuum

12. Hyland, K. (Ed.) (2013). Discourse Studies Reader. London: Bloomsbury.

13. Kopple V., W. (1985). Some exploratory discourse on metadiscourse. College Communication and Composition, 36: 82-93.

14. Lakoff, G. (1973). Hedges: a study in meaning criteria and the logic of fuzzy concepts. Journal of Philosophical Logic, 2(4), 458-508.

15. Piurko, E. (2015). Piurko, P . Discourse Markers: their Function and Distribution in the Media and Legal Discourse. (Ma Thesis).

16. Redeker, G. (1991). `Review Article: Linguistics Markers of Discourse Structure ', Linguistics, Vol. 29, No. 6, pp.1139-1172.

17. Schifrin, D., Tannen, D. \& H. E. Hamilton (Eds.). (2001). The Handbook of Discourse Analysis. Oxford: Blackwell Publishing Ltd.

18. Yilmas, E. (2004). A Practical Analysis of Turkish Discourse Markers: yani, iste andsey. Phd. Thesis. Istanbul: Middle East Technical University

19. Zwicky, A., (1985). Clitics and particles. Language 61 : 283-305. 


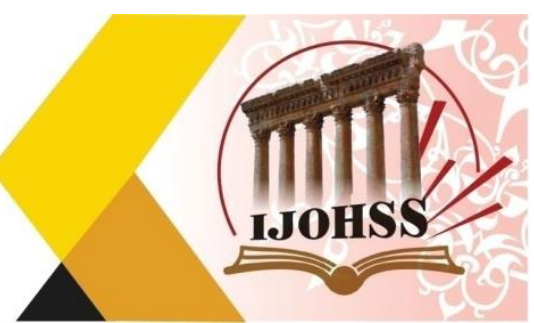

\section{Appendix 1}

The list of editorials of the Guardian newspaper:

Editorials accessed 18/9/2020, available from: https://www.theguardian.com/international.

1. The Guardian view on politics and the environment: we demand better; published Wed 16 Sep 2020. Accessed from

https://www.theguardian.com/commentisfree/2020/sep/16/the-guardian-view-onpolitics-and-the-environment-we-demand-better.

2. The Guardian view on new Brexit borders: the price of political fraud; published Wed 23 Sep. 2020. Accessed from

https://www.theguardian.com/commentisfree/2020/sep/23/the-guardian-view-on-newbrexit-borders-the-price-of-political.

3. The Guardian view on crime and justice: dangerous neglect; published Thu 24 Sep. 2020. Accessed from

https://www.theguardian.com/commentisfree/2020/sep/24/the-guardian-view-on-andjustice-dangerous-neglect.

4. The Guardian view on the EU economy: adopt, not outlaw, Keynesian policies; published 25 Sep. 2020. Accessed from

https://www.theguardian.com/commentisfree/2020/sep/25/the-guardian-view-on-theeu-economy-adopt-not-outlaw-keynesian-policies.

5. The Guardian view on accusations against the military: playing politics with personnel; published Sun 27 Sep 2020. Accessed https://www.theguardian.com/commentisfree/2020/sep/27/the-guardian-view-onaccusations-against-the-military-playing-politics-with-personnel.

6. The Guardian view on Johnson and devolution: another reckless gamble; published Wed.30 Sep. 2020. Accessed from

https://www.theguardian.com/commentisfree/2020/sep/30/the-guardian-view-onjohnson-and-devolution-another-reckless-gamble.

7. The Guardian view on next year's exams: low marks for ministers; published Fri 9 Oct. 2020. Accessed from

https://www.theguardian.com/commentisfree/2020/oct/09/the-guardian-view-on-nextyears-exams-low-marks-for-ministers.

8. The Guardian view on Sunak's U-turn: bad for him but good for the country; published Fri.9 Oct. 2020. Accessed from

https://www.theguardian.com/commentisfree/2020/oct/09/the-guardian-view-onsunaks-u-turn-bad-for-him-but-good-for-the-country. 


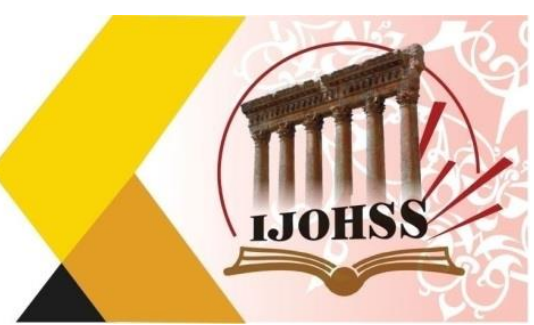

9. The Observer view on Nagorno-Karabakh; published Sun 11 Oct.2020. Accessed from

https://www.theguardian.com/commentisfree/2020/oct/11/the-observer-view-onnagorno-karabakh.

\section{Appendix 2}

The list of editorials of the New York Times newspaper:

Editorials accessed 18/9/2020, available from: https://www.nytimes.com/

1. Vladimir Putin Thinks He Can Get Away With Anything; published Sept. 22, 2020.

https://www.nytimes.com/2020/09/22/opinion/vladimir-putin-navalnypoisoning.html.

2. It Is Time for Swift Action to Keep New Yorkers Safe; published Sept.29, 2020.

https://www.nytimes.com/2020/09/29/opinion/coronavirus-nyc-cuomo-deblasio.html.

3. A Debate That Can't Be Ignored; published Sept.30,2020.

https://www.nytimes.com/2020/09/30/opinion/trump-biden-debate-2020.html.

4. The American People Need the Truth, published Oct.4,2020.

https://www.nytimes.com/2020/10/04/opinion/trump-coronavirus-news.html

5. The Tragedy of Donald Trump; published Oct.22,2020.

https://www.nytimes.com/2020/10/02/opinion/sunday/donald-trump-coronavirus.html 